\title{
Determination of heat losses through building partitions
}

\author{
Tomasz Sobota ${ }^{1, *}$, Jan Taler ${ }^{1}$ \\ ${ }^{1}$ Cracow University of Technology, Institute of Thermal Power Engineering, Faculty of Mechanical Engineering, \\ Al. Jana Pawła II 37, 31-864 Cracow, Poland
}

\begin{abstract}
An numerical algorithm which can be use to calculate heat stream density transferred through wall with air void is presented. Some results of influence of thermal isolation on heat stream density transferred through the wall are presented too. The algorithm shown in this paper has general character and can be use to calculation loss of heat through the walls of block flats, furnaces, cold rooms and others objects and devices.
\end{abstract}

\section{Introduction}

The need to reduce energy consumption and maintain an unchanged temperature inside the building imposes specific requirements with regard to the thermal insulation of external walls and roofs, and thus - the materials used to insulate them.

The choice of the method used to insulate a specific building depends on many factors such as:

1. insulated wall structure,

2. technical condition of the wall,

3. the required thermal and humidity conditions to be met in the insulated building,

4. the financial capacity of the investor. [4]

Increasing the thermal insulation of external walls results in a reduction in energy demand of 15 to $30 \%$ depending on the existing characteristics of the building [3] and the investment outlays, depending on their scale, can be recouped within 1 to 5 years. [1] Also the use of new insulating materials and increased insulation thickness leads to a significant reduction of heat losses through the partitions, and consequently to a reduction in the demand for thermal power in rooms. [2]

Many buildings have external walls made as socalled slotted walls (double), where the air gap, acting as thermal insulation, runs vertically through the height of at least one storey and divides the wall into two: internal (load-bearing) and external (elevation).

Although the air has a low coefficient of heat conduction, the air gap is not a good insulator, which is due to the complex way of transferring heat through the gap. There is both heat exchange through free convection (caused by the temperature difference between the supporting and elevation wall), radiation and conduction. The authors of many publications, e.g. [5-7] in determining the heat flux transmitted through the vertical air gap where natural convection occurs, use a substitute heat conduction coefficient, which is based on the criterion numbers $\mathrm{Gr}, \operatorname{Pr}$ :

$$
\lambda_{k}=\lambda \cdot \frac{0.0236 \cdot(\mathrm{Gr} \cdot \mathrm{Pr})^{1.393}}{(\mathrm{Gr} \cdot \mathrm{Pr})+1.01 \cdot 10^{4}}
$$

However, the equivalent heat conduction coefficient does not take into account heat exchange through radiation.

In this paper we will present an algorithm for calculating the density of heat flowing through a wall with an air gap. It was assumed that the total density of the heat flux passing through the air gap is the sum of three components from convection, conduction and radiation $q=q_{\alpha}+q_{\lambda}+q_{r}$.

\section{Algorithm of calculation of heat loss through walls of buildings}

The calculation of the density of the heat stream penetrating from the inside of the room with the temperature $\mathrm{Tw}_{\mathrm{w}}$ to the environment with the temperature $T_{z}$ will be carried out in an iterative way. This is due to non-linear equations describing heat exchange through natural convection and radiation. At a known internal temperature, the density of the heat flux penetrating through the wall is selected so that the calculated external temperature is equal to the actual external temperature. From the mathematical point of view, a non-linear algebraic equation with one unknown $\mathrm{q}$ is solved.

To solve such an equation, the method of setting the interval has been used in this paper. The calculation of the surface temperature of the air gap from the external environment is also iterative. The surface temperature of the air gap is calculated using the straight iteration method (fixed point method).

At the assumed value $\mathrm{q}$, the surface temperature of the inner wall is calculated first (Fig. 1).

$$
T_{1}=T_{w}-\frac{q}{h_{w}}
$$

where $T_{1}$ - internal wall surface temperature, $T_{w}$ - internal room temperature, $q[\mathrm{~W} / \mathrm{m} 2]$ - heat flux density (unit

\footnotetext{
* Corresponding author: tsobota@mech.pk.edu.pl
} 
heat loss) and $h_{w}$ - heat transfer coefficient from internal air to wall.

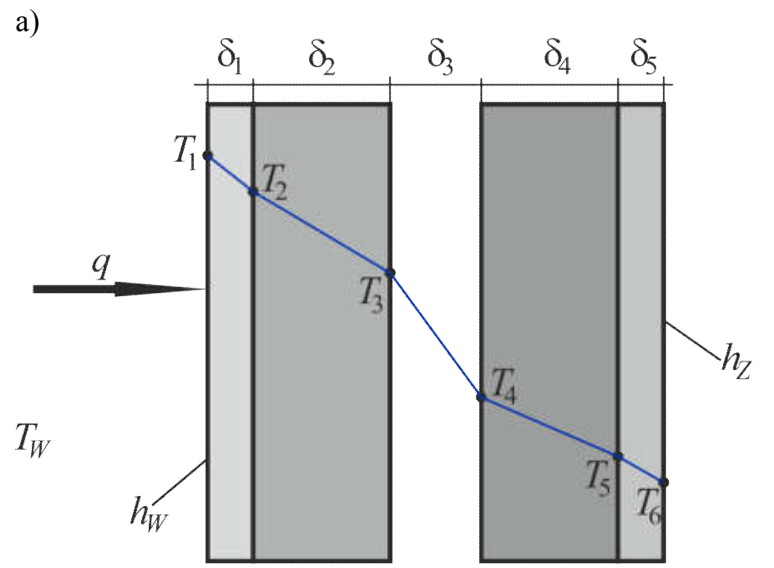

b)

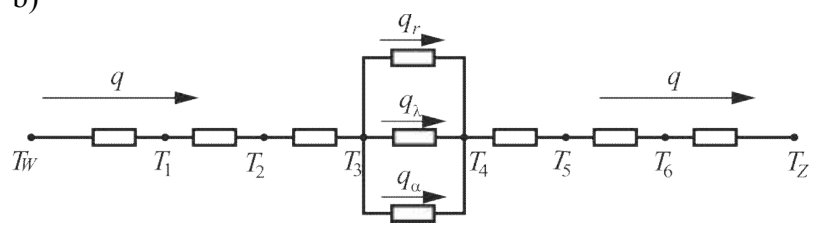

c)

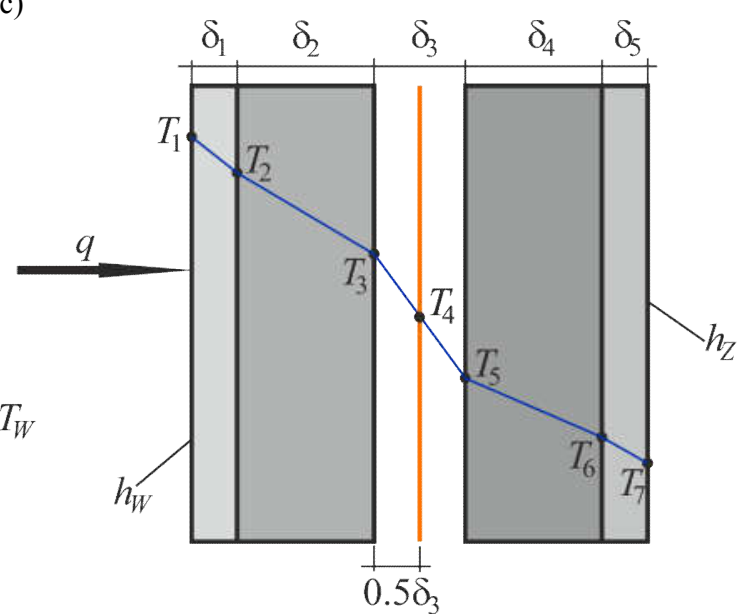

d)

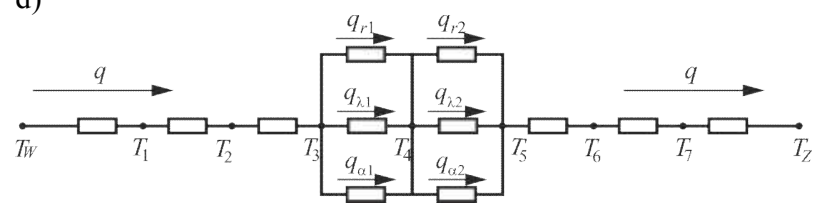

Fig. 1. Scheme of the wall with air void used to computations: a) wall with air void, b) heat flow through the wall diagram, c) wall with air void and radiation shield, d) heat flow through the wall with air void and radiation shield diagram

Then the temperature $T_{2}$ at the plaster-wall boundary is calculated.

$$
T_{2}=T_{1}-\frac{q \cdot \delta_{1}}{k_{1}}=T_{w}-\frac{q}{h_{w}}-\frac{q \cdot \delta_{1}}{k_{1}}=T_{w}-q \cdot\left(\frac{1}{h_{w}}+\frac{\delta_{1}}{k_{1}}\right)
$$

where $\delta_{1}$ - plaster layer thickness, $k_{1}$ - thermal conductivity of the plaster. The temperature $T_{3}$ on the supporting wall surface is calculated consecutively.

$$
\begin{aligned}
& T_{3}=T_{2}-\frac{q \cdot \delta_{2}}{k_{2}}= \\
& =T_{w}-\frac{q}{h_{w}}-\frac{q \cdot \delta_{1}}{k_{1}}-\frac{q \cdot \delta_{2}}{k_{2}}= \\
& =T_{w}-q \cdot\left(\frac{1}{h_{w}}+\frac{\delta_{1}}{k_{1}}+-\frac{\delta_{2}}{k_{2}}\right)
\end{aligned}
$$

where $\delta_{2}$ - load-bearing wall thickness, $k_{3}$ - heat conduction coefficient of the internal wall. Then the temperature $T_{4}$ on the internal surface of the façade wall is iteratively calculated. The total heat flux density through the air gap is determined by the formula:

$$
q=q_{\lambda}+q_{\alpha}+q_{r}
$$

where

- the component of the heat flux transferred by conduction,

$$
q_{\lambda}=\frac{k_{3}}{\delta_{3}} \cdot\left(T_{3}-T_{4}\right)
$$

- convective component of heat flux density,

$$
q_{\alpha}=h_{k}\left(T_{3}-T_{4}\right)
$$

- radiation componen of heat flux.

$$
q_{r}=\frac{\sigma \cdot\left(T_{3}^{4}-T_{4}^{4}\right)}{\frac{1}{\varepsilon_{1}}+\frac{1}{\varepsilon_{2}}-1}
$$

After substitution (5) - (7) to (4) the following is obtained

$$
q=h_{k} \cdot\left(T_{3}-T_{4}\right)+\frac{k_{3}}{\delta_{3}} \cdot\left(T_{3}-T_{4}\right)+\frac{\sigma \cdot\left(T_{3}^{4}-T_{4}^{4}\right)}{\frac{1}{\varepsilon_{1}}+\frac{1}{\varepsilon_{2}}-1}
$$

from where it follows

$$
\left(T_{3}-T_{4}\right)=\frac{q}{h_{k}+\frac{k_{3}}{\delta_{3}}+\frac{\sigma \cdot\left(T_{3}-T_{4}\right) \cdot\left(T_{3}^{2}+T_{4}^{2}\right)}{\frac{1}{\varepsilon_{1}}+\frac{1}{\varepsilon_{2}}-1}}
$$

The temperature $T_{4}$ is calculated from the following equation using the simple iteration method

$$
T_{4}^{(n+1)}=T_{3}-\frac{q}{h_{k}+\frac{k_{3}}{\delta_{3}}+\frac{\sigma \cdot\left(T_{3}-T_{4}^{(n)}\right) \cdot\left[T_{3}^{2}+\left(T_{4}^{(n)}\right)^{2}\right]}{\frac{1}{\varepsilon_{1}}+\frac{1}{\varepsilon_{2}}-1}}
$$

where $n=0,1,2, \ldots$ is the number of subsequent iteration, $\delta_{3}$ - thickness of the air gap, $k_{3}$ thermal conduction of the air, $h_{\mathrm{k}}$ - heat transfer coefficient of the air in the air gap, $\varepsilon_{1}, \varepsilon_{2}$ - emissivity of the surface of load-bearing and elevation wall, $\sigma=5,67 \cdot 10^{-8}$ - Stefan Boltzmann constant, $\mathrm{W} /\left(\mathrm{m}^{2} \mathrm{~K}^{4}\right)$. As the first approximation $(n=0)$ can be taken as $T_{4}{ }^{(0)}=T_{3}-4 \mathrm{~K}$. The iterative process ends when

$$
\left|T_{4}^{(n+1)}-T_{4}^{(n)}\right| \leq \varepsilon
$$

where $\varepsilon$ is the specified tolerance.

The following dependencies were used to determine the convective heat transfer coefficient $\alpha_{\mathrm{k}}$ : [7] 
- for $\mathrm{Gr} \leq 2000$

- $\mathrm{Nu}=$

$$
\mathrm{Nu}=\frac{0.18 \mathrm{Gr}^{0.25}}{\left(\frac{L}{\delta_{3}}\right)^{\frac{1}{9}}}
$$

- for $200000<\mathrm{Gr} \leq 10^{7}$

$$
\mathrm{Nu}=\frac{0.065 \mathrm{Gr}^{\frac{1}{3}}}{\left(\frac{L}{\delta_{3}}\right)^{\frac{1}{9}}}
$$

where $\mathrm{Gr}$ is the Grashoff number $\mathrm{Gr}=\frac{g \rho^{2} \beta x^{3}}{\eta^{2}}\left(T_{w}-T_{\infty}\right)$ and $\mathrm{Nu}$ is the Nusselt number, $\mathrm{L}$ is air gap height.

The temperature $T_{5}$ at the boundary between the external wall and external plaster is then calculated

$$
T_{5}=T_{4}-\frac{q \cdot \delta_{4}}{k_{4}}
$$

where $\delta_{4}$ - external wall thickness, $k_{4}$ - thermal conductivity of the external wall and $T_{6}$ - temperature on the external side of the wall.

$$
T_{6}=T_{5}-\frac{q \cdot \delta_{5}}{k_{5}}=T_{4}-q \cdot\left(\frac{\delta_{4}}{k_{4}}+\frac{\delta_{5}}{k_{5}}\right)
$$

where $\delta_{5}$ - thickness of external plaster, $k_{5}$ - thermal conductivity coefficient of external plaster. The last step is to calculate the ambient temperature $T_{z}$, which is used for comparison with the actual ambient temperature.

$$
T_{z}=T_{6}-\frac{q}{h_{z}}
$$

where $h_{\mathrm{z}}$ is the heat transfer coefficient of the outside air.

The iterative calculation of $q$ shall be carried out using the interval method until the criterion

$$
\left|T_{z}-T_{z, r z}\right| \leq \varepsilon
$$

where $T_{z, \mathrm{rz}}$ is the actual ambient temperature. Usually, only a few iterations are followed by a heat flux density at which the unevenness is met (18). The presented calculation algorithm is general in nature, e.g. there is no small difference between temperatures $T_{3}$ and $T_{4}$ and can be used to calculate heat losses through walls of residential buildings, furnaces, cold rooms and other objects and devices.

\section{Calculation examples}

In order to present the efficiency of the calculation algorithm described above, unit heat losses through the wall of residential buildings of different constructions will be determined. It will be shown that the exchange of heat through radiation in the air gap between the loadbearing wall and the façade wall has a very unfavourable impact on the insulation of the wall, i.e. it contributes significantly to increasing the value of the heat-transfer coefficient through the wall. Examples of calculations were carried out for the following data:
- internal plaster of thickness $\delta_{1}=0.015 \mathrm{~m}$,

- internal wall of thickness $\delta_{2}=0.250 \mathrm{~m}$, made of perforated (cored) brick with thermal conductivity $k_{2}=0.47 \mathrm{~W} /(\mathrm{mK})$,

- air gap of thickness $\delta_{3}=0.060 \mathrm{~m}$,

- external wall of thickness $\delta_{4}=0.120 \mathrm{~m}$ made of solid brick with thermal conductivity $\mathrm{k}_{4}=0.75$ $\mathrm{W} /(\mathrm{mK})$,

- external plaster of thickness $\delta_{4}=0.015 \mathrm{~m}$.

The heat transfer coefficient $h_{\mathrm{z}}$ from the surrounding depends on the wind speed $w$ and is described by the formula [8]

$$
h_{z}=7.15 \cdot w^{0.78}
$$

\section{Discussion of the obtained results}

In the building industry, air void is used to reduce the loss of heat flux density permeating through external walls. The use of this technique allows to limit the density of the heat flux required to maintain the desired temperature in the indoor room by about $17 \%-19 \%$ in relation to the normal wall (for example, used in the calculations). In [4] the recommended minimum thickness of the air gap is $0.04 \mathrm{~m}$. As you can see from Fig. 2. the best effect can be obtained when the width of the air gap is within the range $0.04 \leq \delta_{3} \leq 0.07 \mathrm{~m}$, because the curve representing the dependence of the density of the heat flux as a function of the thickness of the air gap is the steepest in this range. However, with an increase in the thickness of the air gap above $\delta_{3}=0 / 07$ $\mathrm{m}$, the course of the curve is significantly softened (Fig. 2).

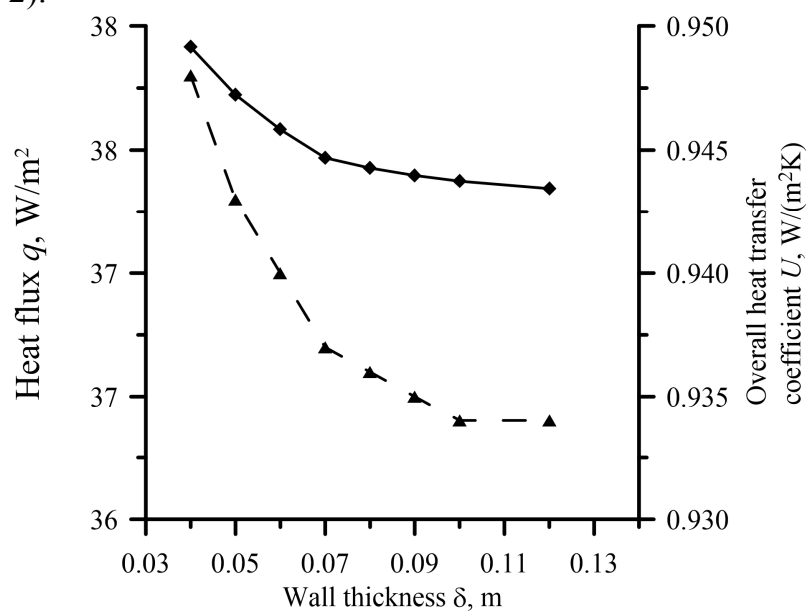

Fig. 2. Effect of thickness of air void on heat stream density and overall heat transfer coefficient

The determined values of the overall heat transfer coefficient $U$ are of the range $0.934 \mathrm{~W} /\left(\mathrm{m}^{2} \mathrm{~K}\right)$ to 0.948 $\mathrm{W} /\left(\mathrm{m}^{2} \mathrm{~K}\right)$ and are on average $18 \%$ lower than for a normal wall $\left(U=1.150 \mathrm{~W} /\left(\mathrm{m}^{2} \mathrm{~K}\right)\right)$ made of the same materials.

In the air gap, the density of the heat flux is transmitted through three paths: convection, radiation and conduction (Fig. 1). The following table shows the shares of the individual heat transfer methods in the total heat transfer stream. 
Table 1. Font styles for a reference to a journal article.

\begin{tabular}{|c|c|}
\hline $\begin{array}{c}\text { Method of heat } \\
\text { transfer }\end{array}$ & Percentage of total heat flux \\
\hline Conduction & $7.8 \%$ \\
\hline Convection & $19.51 \%$ \\
\hline Radiation & $72.69 \%$ \\
\hline
\end{tabular}

These shares were determined for the case when the wall with an air void was not insulated. As you can see, almost three quarters of the heat flux is transmitted through radiation in the gap. Reducing the share of radiation in the total heat flux density passing through the partition by using screens inside the air gap can be one of the ways to reduce heat loss in the room. In the case of using a single screen with the same emissivity as the masonry, the density of the heat flux transmitted by the radiation is reduced twice. In order to determine the effect of the screen on the total heat flux density that penetrates through the partition, numerical calculations have been made for the following case. In the wall with an air void as presented in Section 3. The air gap was divided into two parts by a screen made of polished aluminium foil. The diagram of a building envelope with an aluminium foil screen and the corresponding thermal resistance system is shown in Fig. 1c and Fig. 1d. As a result of this procedure, the share of radiation in the total heat flux density was reduced to $11 \%$ in the first part of the air gap and to $11.6 \%$ in the second part, and the of heat flux transferred through the building wall decreased from $37.583 \mathrm{~W} / \mathrm{m}^{2}$ in the case of a wall with an unshielded air gap, to $21.194 \mathrm{~W} / \mathrm{m}^{2}$ after the use of aluminium foil.
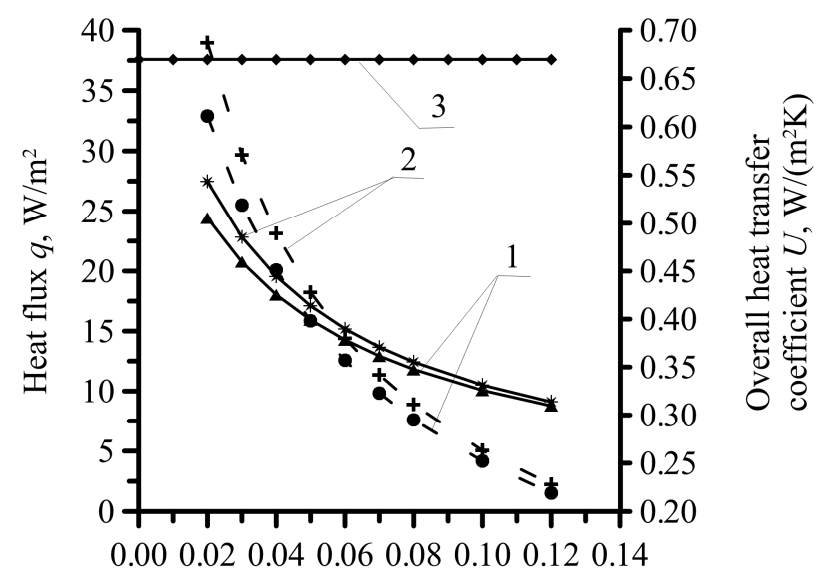

Wall thickness $\delta, \mathrm{m}$

Fig. 3. Effect of additional thermal isolation (foamed polystyrene $\left.\lambda=0,034 \mathrm{~W} /\left(\mathrm{m}^{2} \mathrm{~K}\right)\right)$ of the wall with air void on heat stream density and overall heat transfer coefficient.

The next stage of calculations was an attempt to determine the effect of additional external insulation of the wall with air void on the heat flux density and a comparison with the case of thermal insulation of the same thickness but placed between the supporting and elevation wall - Fig. 3. As can be seen in Fig. 3 the very application of insulation with minimum thickness (in both cases), gives visible effects in the form of reduced density of the heat flux. For example, for a $0.06 \mathrm{~m}$ thick thermal insulation, in both cases a reduction of heat flux density by more than $60 \%$ was achieved. For the thickness of the foamed polystyrene layer equal to 0.06 m one obtains $q=14.27 \mathrm{~W} / \mathrm{m}^{2}$ when the wall is insulated from the outside and $q=15.19 \mathrm{~W} / \mathrm{m}^{2}$ when the insulation is inside the partition. In the case of external insulation, the losses are reduced by $\frac{(15,19-14,27)}{15,19} \cdot 100 \%=6,1 \%$.

It can be noticed that insulating the wall from the outside is more advantageous in terms of thermal insulation. For technological reasons, it is more advantageous to build walls with internal insulation (smaller thickness of the wall, there is no need to use metal anchors), however, the argument for a wall with an air void with additional insulation from the outside is in addition to reducing heat losses also a more favourable distribution of temperatures $T_{3}$ and $T_{4}$ on the surfaces of the air gap and the temperature of the façade wall $T_{5}$.

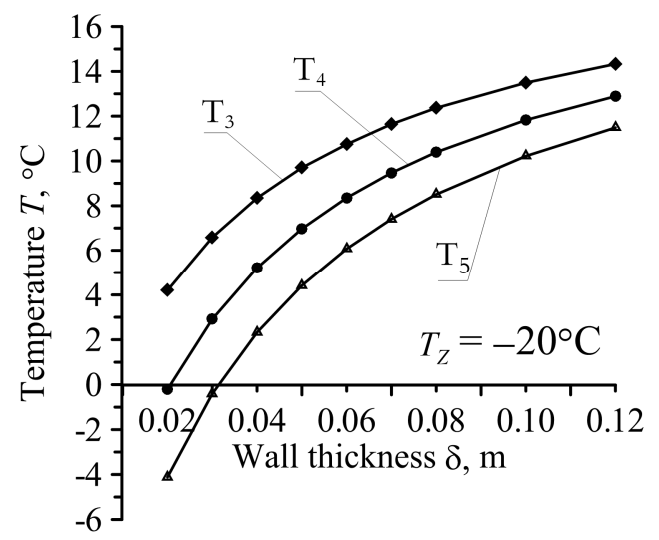

Fig. 4. Effect of thickness insulating material on $T_{3}$ i $T_{4}$ temperatures on the air void surfaces and $T_{5}$ temperature outside the wall

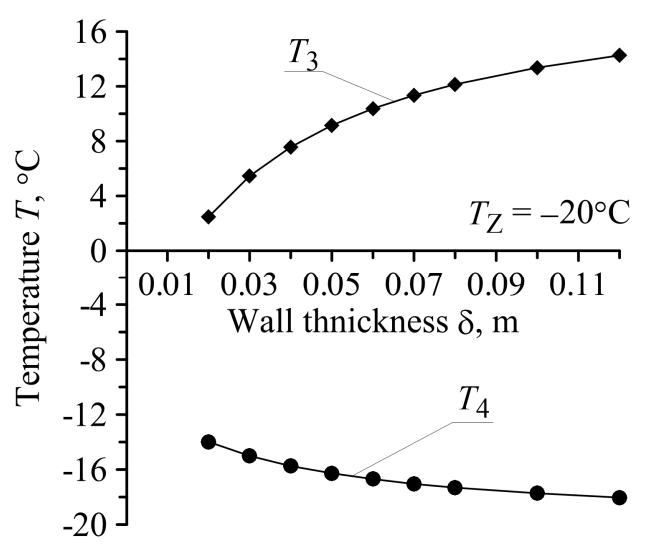

Fig. 5. Changes of $T_{3}$ i $T_{4}$ temperatures (Fig. 1a) when the air void is filled by different thickness insulating material

As shown in Fig. 4. for this type of partition there is almost no freezing of the external wall. On the other hand, if the insulation is placed inside the wall, the façade wall in the winter period is still working at negative temperatures, regardless of the ambient 
temperature, if only the latter is lower than zero (Fig. 6). In order to show the benefits of thermal insulation of external partitions, the wall thickness distribution for the following models of building partitions is shown in Fig. 7 wall with a non-heat-insulated air gap, wall with a screened air void and wall with a screened air gap with thermal insulation from the outside.

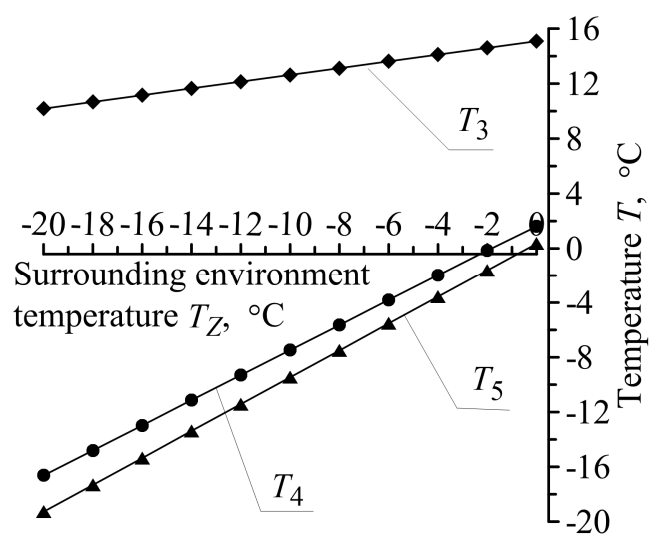

Fig. 6. Changes of $T_{3}$ i $T_{4}$ temperatures (Fig. 1a) when the air

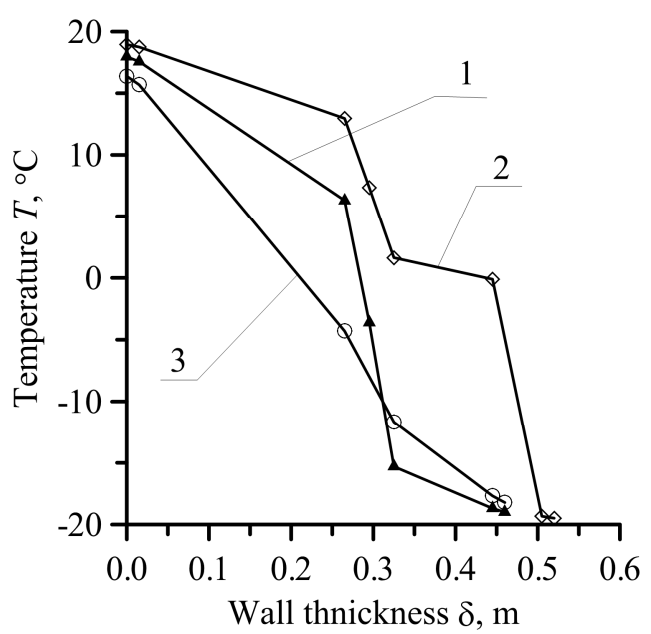

Fig. 7. Wall temperature distribution: 1 - wall with air void equipped with a radiation shield, 2 - wall with air void equipped with a radiation shield and outer thermal insulation, 3 - wall with air void

a)

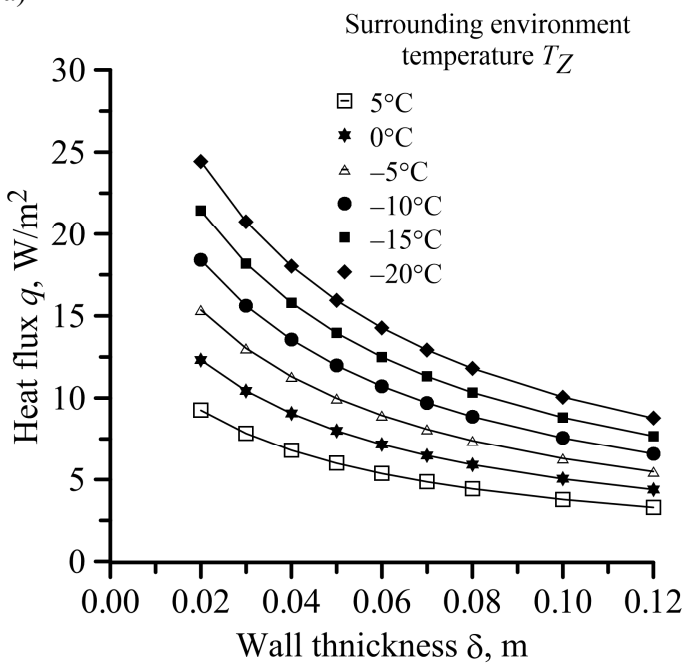

b)

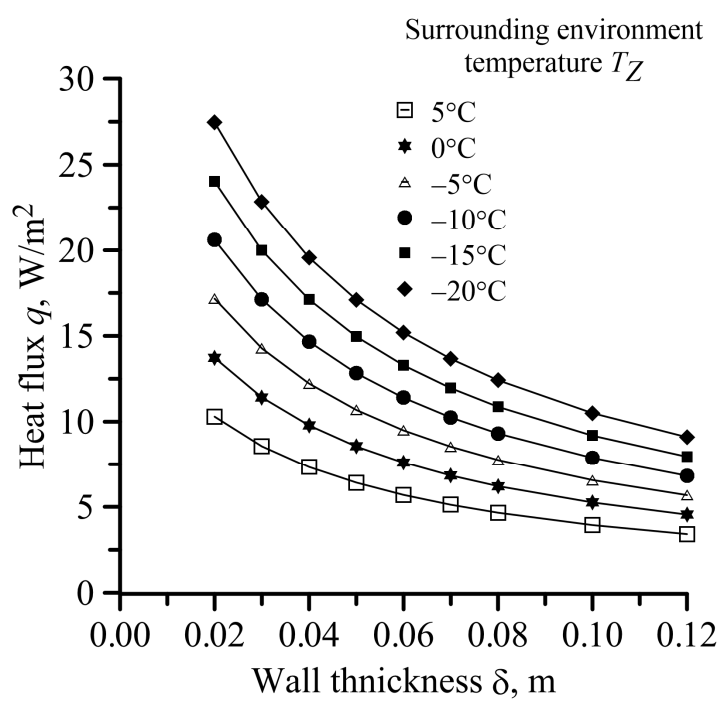

Fig. 8. Wall temperature distribution: 1 - wall with air void equipped with a radiation shield, 2 - wall with air void equipped with a radiation shield and outer thermal insulation, 3 - wall with air void

Fig. 8 shows the change of unit heat loss at the assumed temperature inside the room, at different outside temperatures, as a function of the thickness of the applied insulation. In the range of ambient temperatures from $-5^{\circ} \mathrm{C}$ to $-20^{\circ} \mathrm{C}$ these curves are very steep, which means that a slight increase in the thickness of the applied insulation contributes to a significant reduction in the loss of heat flux density, and at the same time lowers the costs of space heating. Assuming an extreme case, that the outside temperature in winter is $-20^{\circ} \mathrm{C}$ and insulating the wall with a layer of $0.10 \mathrm{~m}$ foamed polystyrene, whose thermal conductivity $k=$ $0.034 \mathrm{~W} /(\mathrm{mK})$, it is possible to reduce the heat flux transferred through the wall of the order of 3.7 times in relation to the non-insulated wall (Fig. 8a). The heat flux for such insulated wall is $q=10.06 \mathrm{~W} / \mathrm{m}^{2}$ and the overall heat transfer coefficient $U=0.252 \mathrm{~W} /\left(\mathrm{m}^{2} \mathrm{~K}\right)-$ Fig. 8a. Similar results were achieved in the case of thermal insulation inside the partition (Fig. 8b).

The insulation material also has a great influence on the reduction of heat flux density. It should be characterized by resistance to moisture and the lowest possible coefficient of heat conduction.

\section{Final remarks}

The general algorithm of calculation of heat losses through building partitions presented in the paper allows to determine heat losses taking into account convection and radiation in the air gap. It enables determination of thermal losses through building partitions and the distribution of temperatures on its thickness much more precisely than in the case of algorithms taking into account only the heat conduction resistance of individual layers. 


\section{References}

1. Regulation of the Minister of Infrastructure and Construction of the Republic of Poland on technical conditions to be met by buildings and their location. Journal of Acts, 1422 (2015)

2. J. Kwiatkowski, P. Matwiejuk, District Heating, Heating, Ventilation, 9, pp. 325-329 (1994)

3. R. Rabjasz, District Heating, Heating Ventilation, 6, pp. $250-256$ (1995)

4. J. Panas (Ed.), New construction foreman's guide (ARKADY, Warsaw 2007)

5. F. Hell, Grundlagen der Wärmeübertragung, (VDI Verlag, Düsseldorf, 1979)

6. W.P. Isachenko, W.A. Osipowa, A.S. Sukomiel, Tieplopieredacha (Energiya, Moscow, 1965)

7. J.R. Welty, Engineering heat transfer (John Wiley \& Sons Inc., New York, 1974)

8. H. Recknagel, E. Sprenger, E.-R.Schramek, Heating and air conditioning manual including refrigeration and hot water supply (EWFE, Gdańsk, 1994) 